\title{
Auditory Intellectually Repetition: Apakah Berdampak Pada Kemampuan Pemahaman Geometri Siswa Berkemampuan Rendah?
}

\author{
Runisah $^{1 *}$, Denni Ismunandar ${ }^{2}$, Sudirman $^{3}$, Yossa Giovani Vianto $^{4}$ \\ 1,2,3,4Pendidikan Matematika, Universitas Wiralodra, Indramayu, Indonesia; \\ 1*runisah@unwir.ac.id; ${ }^{2}$ denni.ismunandar@unwir.ac.id; ${ }^{3}$ sudirman@unwir.ac.id; \\ 4yossagv@gmail.com
}

Info Artikel: Dikirim: 8 Oktober 2020 ; Direvisi: 2 Maret 2021; Diterima: 9 Maret 2021

Cara sitasi: Runisah, R., Ismunandar, D., Sudirman, S., \& Vianto, Y. G. (2021). Auditory Intellectually Repetition: Apakah Berdampak pada Kemampuan Pemahaman Geometri Siswa Berkemampuan Rendah?. JNPM (Jurnal Nasional Pendidikan Matematika) 5(1), 125-135.

\begin{abstract}
Abstrak Beberapa penelitian terdahulu menunjukkan kemampuan pemahaman matematis khususnya dalam geometri masih rendah. Metode yang relevan diperlukan sebagai upaya meningkatkan kemampuan tersebut. Penelitian Quasi eksperimen dengan Static Group Comparison Design ini mempunyai tujuan untuk mengetahui dampak proses belajar menggunakan Auditory Intellectually Repetition (AIR) terhadap kemampuan pemahaman matematika siswa berkemampuan rendah. Subjek penelitian berjumlah 63 siswa kelas VII salah satu sekolah yang memiliki nilai Ujian Nasional (UN) matematika di bawah rerata nilai UN matematika di Indramayu, Jawa Barat. Dua kelas diambil dengan acak dari seluruh kelas VII, satu kelas mendapatkan pembelajaran dengan model AIR, sedangkan satu kelas yang lain mendapat pembelajaran konvensional. Instrumen berupa tes kemampuan pemahaman geometri berbentuk uraian. Berdasarkan penelitian ini model AIR berdampak secara signifikan pada kemampuan pemahaman geometri siswa berkemampuan rendah. Implikasi dari penelitian ini adalah siswa yang memiliki kemampuan rendah membutuhkan model pembelajaran yang tepat.
\end{abstract}

Kata Kunci: model pembelajaran, Auditory Intellectually Repetition, pemahaman Geometri, siswa berkemampuan rendah.

Abstract. Some previous studies have shown that the ability of mathematical understanding, especially in Geometry, is still low. Relevant methods need to be developed in an effort to improve these capabilities. The Design aims to assess the effect of the learning process using Auditory Intellectually Repetition (AIR) on the ability of low-ability students to understand mathematics. The research subjects consisted of 63 grade VII students of one of the schools with a Mathematics National Exam (UN) score below the average score of the Mathematics UN in Indramayu, West Java. Two classes were taken randomly from all seventh grade students, one class received learning using the AIR model, while the other class received conventional learning. The instrument used is an essay test of geometry understanding ability. Base on this study, the AIR model has a significant effect on the ability of lowability students to understand geometry. The implication of this study is that students with low abilities need an appropriate learning model.

Keywords: learning model, Auditory Intellectually Repetition, understanding Geometry, low ability students. 


\section{Pendahuluan}

Pemahaman yang utuh dan fungsional terhadap ide matematika desebut sebagai pemahaman konsep matematika (Kilpatric, Swafford, \& Findel, 2001). Pemahaman matematis merupakan dasar untuk berpikir dalam menyelesaikan masalah matematis dan masalah di kehidupan sehari-hari (Lambertus, 2016) dan sebagai bagian yang tidak bisa dipisahkan dari pemecahan masalah matematika, sedangkan pemecahan masalah itu sendiri merupakan inti dari mengerjakan matematika (Minarni, Napitupulu, \& Husein, 2016). Artinya tujuan pembelajaran berbagai konsep matematika adalah untuk melakukan pemecahan masalah, melalui pemecahan masalah siswa mengembangkan jenis kemampuan matematika lain seperti pemahaman matematika (Minarni, Napitupulu, \& Husein, 2016). Didasarkan pada hal tersebut, kemampuan dalam memahami konsep matematika merupakan dasar utama untuk membangun kompetensi matematika tingkat tinggi (Sumartini \& Priatna, 2018) dan membantu siswa untuk menghindari kesalahan dalam mengaplikasikan matematika dalam kehidupan sehari-hari (Al-Mutawah, Thomas, Eid, Mahmoud, \& Fateel, 2019).

Salah satu bidang yang diajarkan di sekolah yaitu geometri. Materi yang dipelajari siswa terkait dengan geometri merupakan bidang yang penting diajarkan mulai dari jenjang sekolah dasar untuk melatih berfikir logis (Novianti, 2015). Materi geometri tersebut diantaranya mengkaji tentang unsur unsur bidang dan ruang serata berbagai sifat dan ukuran (Nur'aini, Harahap, Badruzzaman, \& Darmawan, 2017).

Pentingnya kemampuan pemahaman geometri menjadikan kemampuan tersebut sebagai salah satu tujuan diberikannya matematika. Hal itu dijelaskan dalam Permendikbud No 35 tahun 2018 bahwa tujuan pembelajaran matematika yaitu dipahaminya konsep dan diterapkannya prosedur matematika dalam kehidupan sehari-hari oleh siswa, siswa dapat melakukan operasi matematika, siswa mampu melakukan penalaran matematis, menyelesaikan masalah dan mengkomunikasikan gagasan (Kemendikbud, 2018). Selain itu jika dilihat dari seberan kompetensi dasar (KD) matematika, untuk satuan pendidikan Sekolah Dasar (SD) porsi geometri cukup besar (35\%) dibandingkan statistika dasar (10\%) (Sudirman \& Martadiputra, 2020). Untuk standar kompetensi satuan pendidikan SMP, porsi geometri dan aljabar paling besar dibandingkan materi lain, masing- masing 33,33\% dari keseluruhan materi (Sudirman \& Martadiputra, 2020).

Walaupun pada sebaran kurikulum matematika di sekolah porsi geometri cukup besar, namun ada ketidakpuasan dalam penguasan konsep geometri di Indonesia jika merujuk temuan dari Trends in International Mathematics and Science Study (TIMSS). Dalam geometri, dari hasil TIMSS tahun 2007 siswa memperoleh rata rata nilai capaian 395 (39,5\%) (Mullis, Martin, \& Foy, 2008), tahun 2011 memperoleh rata-rata 377 (37,7\%) (Mullis, Martin, Foy, \& Arora, 2012), dan tahun 2015 mencapai nilai 394 (39,4\%) (Mullis, Martin, Foy, \& Hooper, 2016. Dari hasil temuan TIMSS menunjukkan kemampuan siswa dalam materi geometri masih rendah. 
Selain hasil temuan TIMSS, secara lebih khusus di Kabupaten Indramayu hasil Ujian Nasional (UN) matematika tahun 2018 dan 2019 masih rendah dibandingkan dengan rata rata nilai UN matematika tingkat provinsi dan secara nasional,. Pada tahun 2018 rata rata nilai UN matematika secara nasional 43,34, di tingkat provinsi Jawa Barat 46,07, dan di Kabupaten Indramayu 34,40. Pada tahun 2019 rata rata nilai UN matematika secara nasional 45,08, di tingkat provinsi 43,95 dan di Kabupaten Indramayu 39,74. Rata-rata nilai tersebut merupakan rata-rata total untuk sekolah negeri dan swasta (Kemendikbud, 2019). Mengingat bahwa porsi geometri dan aljabar mempunyai porsi terbesar (33,33\%) (Sudirman \& Martadiputra, 2020) dan rendahnya kemampuan siswa dalam geometri menurut hasil TIMSS, maka rendahnya nilai rata rata UN mengindikasikan masih rendahnya kemampuan pemahaman siswa terhadap konsep-konsep matematika, khususnya pemahaman terkait konsep geometri

Agar siswa memahami konsep geometri dengan baik, berbagai upaya diperlukan. khususnya bagi siswa berkemampuan rendah. Siswa dengan kemampuan matematika yang rendah memerlukan penanganan yang lebih baik dari guru. Hal itu dikarenakan rendahnya kemampuan tersebut menunjukkan adanya kesulitan belajar pada siswa. Capaian belajar yang rendah mencirikan adanya kesulitan belajar siswa sehingga guru harus dapat menciptakan suatu situasi agar siswa lebih mudah dalam belajar (Nasution, Rangkuti, Hilda, 2019).

Banyak faktor yang menyebabkan rendahnya kemampuan pemahaman konsep matematika, yaitu faktor dari siswa seperti gaya kognitifnya (Sudirman, Son, Rosyadi, \& Fitriani, 2020) atau karena proses pembelajarannya (Sumartini \& Priatna, 2018). Perbaikan proses kegiatan belajar dapat dilaksanakan sesuai dengan model yang dapat menjadikan kemampuan siswa pada aspek kognitif lebih meningkat (Eriana, Kartono, \& Sugianto," 2018). Satu diantara beberapa model dalam proses belajar yang dapat memacu siswa dalam memahami konsep-konsep matematika yaitu model Auditory Intellectually Repetition (AIR). Menurut Rohaeti, Hendriana, \& Sumarmo (2019) model AIR melibatkan tiga aspek. Auditory yaitu proses belajar yang dilakukan siswa melalui kegiatan mendengarkan, menyimak, dan berkomunikasi secara lisan. Intellectually yaitu siswa belajar dengan menggunakan kemampuan berpikir (minds-on). Repetition yaitu pemantapan terhadap penguasaan konsep konsep yang dipelajari siswa melalui pengulangan

Selanjutnya Manurung (2016) mengungkapkan bahwa suatu model efektif jika dalam pelaksanaan proses pembelajaraan memperhatikan tiga hal, yaitu auditory, intellectually, dan repetition. Pada aspek auditory, siswa terlatih untuk mengkomunikasikan ide-ide melalui diskusi dan mepresentasikan hasil diskusi. Proses tersebut mempermudah guru mengontrol pemahaman siswa untuk 
memberikan tindak lanjut yang sesuai untuk diberikan oleh guru. Mustamin \& Kusumayanti (2019) menjelaskan bahwa siswa dikatakan memahami suatu konsep apabila dapat mengungkapkan kembali konsep tersebut dalam bahasa sendiri. Pada aspek intellectually, siswa melakukan eksplorasi untuk memecahkan masalah. Kegiatan eksplorasi akan memperdalam pemahaman matematis siswa (Runisah, Herman, \& Dahlan, 2017). Sedangkan melalui repetition atau pengulangan berupa latihan soal, akan memperdalam pemahaman siswa. Pengulangan penting agar siswa lebih mendalami dan memperluas pemahamannya (Manurung, 2016)

Penelitian penggunaan model AIR telah banyak dilakukan. Hasil penelitian menyimpulkan, model AIR berpengaruh terhadap kemampuan siswa dalam menyelesaikan masalah matematis (Ramdhan, Suwarman, Candra, 2017'; Agustiana, Putra, \& Farida, 2018; Aprianti \& Kesumawati, 2019). Selain itu, hasil penelitian lainnya juga menyimpulkan bahwa penggunaan model AIR berpengaruh terhadap kemampuan siswa memahami konsep matematis (Sarniah, Anwar, \& Putra, 2019; Asfar, Asmawaty, \& Nursyam., 2019).

Meskipun telah ada beberapa penelitian yang mengkaji tentang penggunaan model AIR, namun penelitian tentang penerapan model AIR pada siswa berkemampuan rendah belum penulis temukan. Oleh sebab itu, penelitian ini bertujuan untuk mengkaji dampak dari penerapan model AIR terhadap kemampuan pemahaman geometri siswa berkemampuan rendah di sekolah menengah pertama yang ada di Kabupaten Indramayu.

\section{Metode}

Penelitian dilakukan melalui quasi eksperimen dengan Static Group Comparison Design. Observasi dilakukan terhadap kedua kelompok sebanyak satu kali yaitu sesudah perlakuan (post-test) (Fraenkel, Wallen, \& Hyun, 2012). Untuk menentukan siswa yang berkemampuan rendah, dari seluruh sekolah yang mempunyai nilai rerata UN matematika di bawah nilai rerata UN matematika di Indramayu dipilih satu sekolah secara acak. Selanjutnya dari kelas VII sekolah tersebut, 2 kelas diambil dengan cara acak, satu kelas melalui pembelajaran yang pada umumnya dilakukan di sekolah (model konvensional), sedangkan kelas lain menggunakan model AIR. Sekolah terpilih memiliki rata-rata UN matematika tahun 2018 dan 2019 berturut turut dengan nilai 29,83 dan 34,77. Perolehan tersebut berada cukup jauh di bawah nilai rata rata UN siswa SMP/MTS di Indramayu. Jika dibandingkan dengan nilai rata rata UN matematika dalam skala nasional yaitu sebesar 43,34 pada tahun 2018 dan 45,08 pada tahun 2019, , perolehan nilai tersebut berada di bawah rata-rata. Selain itu berdasarkan hasil ulangan harian siswa sebelumnya nilai rata-rata keseluruhan siswa kelas VII yaitu 59,0. Untuk kelas eksperimen dengan nilai 56,09 dan untuk kelas kontrol sebesar 61, 7.7 Nilai rata rata tersebut di bawah kriteria ketuntasan minimal (KKM) yaitu 75. Hal ini menggambarkan bahwa sampel yang diambil merupakan siswa yang berkemampuan rendah. 
Instrumen yang digunakan dalam penelitian berupa tes kemampuan pemahaman geometri siswa, terdiri dari enam soal berbentuk uraian. Berdasarkan hasil uji coba, diperoleh bahwa instrumen valid dan reliabel dengan koefisien reliabilias $r=0,69$. Indikator pemahaman konsep geometri terdiri dari (1) menyatakan ulang konsep keliling dan luas segitiga; (2) menjelaskan konsep keliling dan luas segitiga; (3) menggunakan konsep keliling dan luas segitiga dalam mencari solusi pemecahan masalah; (4) menghubungkan konsep keliling dan luas segitiga dengan konsep lain. Selanjutnya analisis data menggunakan uji-t untuk melihat dampak penggunaan model AIR terhadap kemampuan konsep geometri siswa berkemampuan rendah. Sebelum dilakukan uji - $t$, terlebih dahulu digunakan uji prasyarat yaitu uji normalitas data dengan uji Liliefors dan uji homogenitas varians dengan menggunakan uji- $F$.

Selanjutnya, tahapan model AIR yang digunakan didasarkan pada pendapat Herdianti (Rohaeti, Hendriana, \& Sumarmo, 2019). Langkah-langkah model AIR saat penelitian, tertera pada Tabel 1 .

Tabel 1. Tahapan Model AIR

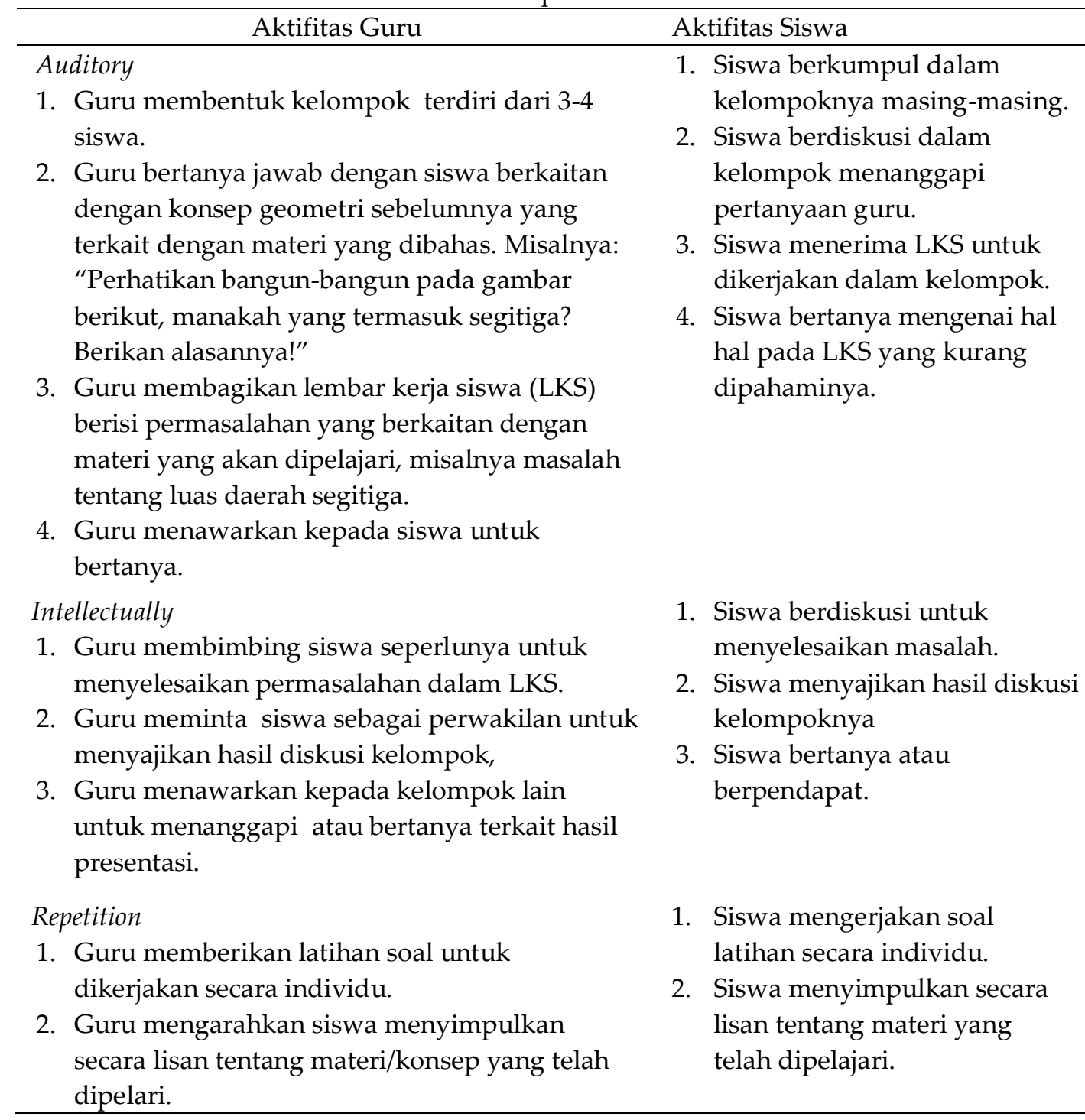


Tabel 1 merupakan contoh kegiatan pembelajaran dengan model AIR pada salah satu materi penelitian yaitu luas daerah segitiga.

\section{Hasil dan Pembahasan}

Setelah selesai pembelajaran selama 6 pertemuan, kemudian di akhir pertemuan peneliti melakukan post-test kemampuan pemahaman geometri siswa. Hasil tes kemampuan pemahaman geometri siswa pada kedua kelompok eksperimen disajikan pada Gambar 1.

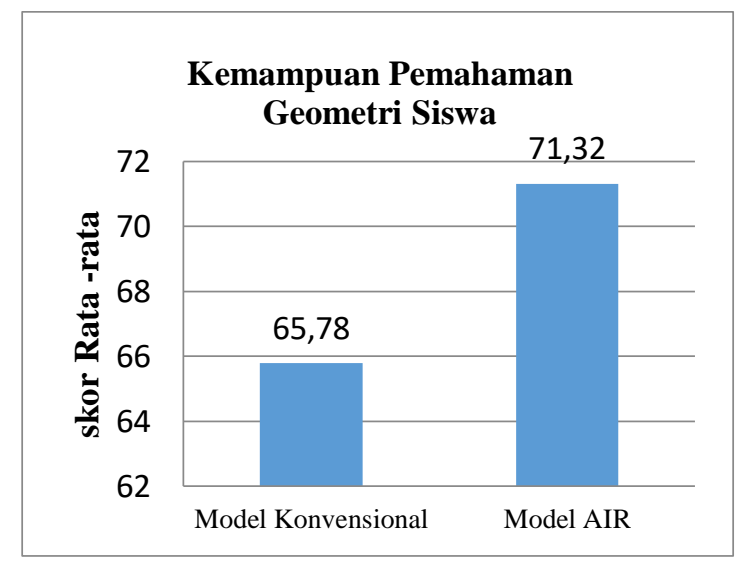

Gambar 1. Skor rata rata kemampuan pemahaman geometri siswa.

Pada Gambar 1 terlihat bahwa kemampuan pemahaman geometri siswa dengan model AIR lebih baik dari siswa dengan model konvensional. Namun demikian jika dibandingkan dengan nilai KKM yaitu 75, pemahaman siswa belum mencapai ketuntasan minimal.

Sebelum peneliti melakukan pengujian hipotesis, uji normalitas dilakukan terlebih dahulu untuk mengetahui normalitas distribusi kedua populasi. Uji Lilliefors digunakan untuk keperluan pengujian tersebut pada taraf signifikansi $(\alpha) 5 \%$. Ringkasan hasil uji tertera pada Tabel 2.

Tabel 2. Data Hasil Uji Normalitas

\begin{tabular}{lccc}
\hline \multicolumn{1}{c}{ Kelas } & $\mathrm{N}$ & $\boldsymbol{L}_{\mathbf{0}}$ & $\boldsymbol{L}_{\boldsymbol{u j i}}$ \\
\hline Model Konvensional & 32 & 0,0787 & 0,1566 \\
Model AIR & 31 & 0,1005 & 0,1591 \\
\hline
\end{tabular}

Tabel 2 menunjukkan bahwa $L_{0}$ yang diperoleh kelas model konvensional yaitu 0,0787 dengan $L_{u j i}$ yaitu 0,1566 . Sedangkan $L_{0}$ yang diperoleh kelas Model AIR yaitu 0,1005 dengan $L_{u j i}$ yaitu 0,1591. Karena $L_{0}<L_{u j i}$, maka kedua kelas tersebut berasal dari populasi yang memiliki distribusi normal. 
Selanjutnya, uji homogenitas dilakukan untuk mengetahui varians dari kedua populasi, homogen ataukah tidak, sehingga dapat ditentukan langkah untuk pengujian hipotesis. Hasil perhitungan pengujian tersebut disajikan pada Tabel 3.

Tabel 3. Hasil Uji Homogenitas Varians

\begin{tabular}{cccccc}
\hline Kelas & $\mathrm{N}$ & Varians & $\mathrm{F}_{0}$ & $\mathrm{~F}_{\mathrm{uji}}$ & Keterangan \\
\hline Model Konvensional & 32 & 76,4346 & \multirow{2}{*}{1,1743} & \multirow{2}{*}{2,0657} & varians \\
Model AIR & 31 & 89,7591 & & & homogen \\
\hline
\end{tabular}

Tabel 3 menunjukkan bahwa varians pada kelas model konvensional yaitu 76,4346 sedangkan pada kelas model AIR yaitu 89,7591, sehingga diperoleh nilai $F$ yaitu 1,1743. Karena $F_{0}<F_{u j i}$, maka varians kedua populasi homogen.

Pengujian hipotesis penelitian menggunakan independent sample t-test dengan taraf signifikansi $(\alpha) 5 \%$. Berdasarkan hasil pengolahan data diperoleh nilai statistik $t$ sebesar -2.4138 dan $t_{\text {kritis }}=1.6702$. Karena hasil perhitungan di atas menunjukkan bahwa $t<-t_{\text {kritis }}$, maka $H_{0}$ ditolak. Artinya kemampuan pemahaman geometri siswa dengan menerapkan model AIR lebih baik dari siswa yang memperoleh model konvensional. Dengan demikian penggunaan model AIR berpengaruh terhadap kemampuan pemahaman geometri siswa berkemampuan rendah.

Berdasarkan hasil penelitian, penggunaan model AIR berpengaruh pada kemampuan pemahaman siswa dalam geometri. Hal ini disebabkan lebih aktifnya siswa selama kegiatan pembelajaran. Para siswa nampak lebih bersemangat dalam berdiskusi kelompok. Merekapun sangat antusias ketika mempresentasikan hasil diskusi sementara kelompok lain aktif mendengarkan dan memberikan pendapat. Begitupun saat para siswa diberi latihan sebagai bentuk pengulangan, mereka bersemangat dalam mengerjakannya. Kenyataaan yang ada pada saat penelitian tersebut sejalan dengan pendapat Shoimin (2014) bahwa pada model AIR siswa lebih aktif mengungkapkan idenya, memanfaatkan secara mendalam kemampuan yang mereka miliki, siswa bersemangat dalam memberikan penjelasan, dan siswa memiliki lebih banyak pengalaman dalam mencari solusi penyelesaian masalah.

Selanjutnya, berbagai penyebab adanya dampak positif penggunaan model AIR terhadap kemampuan pemahaman geometri siswa dapat dijelaskan dari tahapan pembelajaran yang dilaksanakan saat penelitian. Pada aspek Auditory, siswa dilatih untuk dapat mengkomunikasikan ide dan pemikirannya baik di antara teman sekelompoknya, maupun di depan seluruh teman sekelasnya. Dengan demikian pemahaman siswa akan lebih terpacu. Hal ini sejalan dengan Mustamin \& Kusumayanti (2019) bahwa siswa dikatakan paham bukan berarti siswa hanya sekedar mengetahui dan mengingat, namun dapat mengungkapkan kembali suatu konsep dengan kalimatnya sendiri. Pada aspek intelectualy, siswa diberikan masalah terkait dengan konsep atau materi yang dipelajarinya. Siswa dilibatkan dalam kegiatan eksplorasi untuk memecahkan masalah tersebut. Melalui kegiatan eksplorasi, pemahaman siswa terhadap konsep yang dipelajarinya akan lebih mendalam (Runisah, Herman, \& Dahlan, 2017). Pada aspek pengulangan (repetition) 
yang berupa pendalaman materi berupa tugas individu, sangat menunjang terhadap pemahaman materi secara menyeluruh. Pengulangan penting dilakukan agar pemahaman siswa lebih komprehensif (Manurung, 2016). Berlatih rutin dalam menerapkan berbagai aturan dan berbagai metode matematis dapat menjadikan dasar bagi siswa untuk menguasai prosedur, operasi, dan keterampilan matematis (Tularam \& Machisella, 2018)

Model AIR juga didukung oleh teori belajar aliran psikologis tingkah laku. Materi akan lebih kuat tersimpan dalam ingatan apabila materi tersebut sering diulangi (Amsari, 2018). Pengulangan terjadi dalam aspek repetition dimana guru memberikan latihan. Teori lain yang mendukung model AIR yaitu teori aliran psikologi kognitif. Menurut aliran ini siswa membangun pengertian sendiri ketika mereka mempelajari konsep konsep matematika. Menurut Piaget, makna yang lebih baik terhadap berbagai objek akan diperoleh ketika anak berinteraksi secara aktif dengan lingkungannya (Tuna \& Kacar, 2013). Pada model AIR interaksi aktif antara siswa melalui diskusi kelompok akan menjadikan belajar lebih bermakna bagi siswa. Selain itu karena guru tidak memberikan langsung konsep konsep yang dipelajarinya, tetapi diperoleh melalui masalah yang ada pada lembar kerja, maka siswa membangun pengetahuan mereka sendiri. Guru hanya memfasilitasi siswa dalam belajar, yang terpenting adalah proses belajar peserta didik.

Sementara itu, dalam pembelajaran konvensional yang dilakukan pada kelas kontrol, guru menjelaskan konsep atau materi yang dipelajari, siswa mendengarkan penjelasan guru. Selanjutnya guru memberikan latihan soal. Dengan demikian siswa kurang dilibatkan dalam aktivitas berpikir, mengeluarkan pendapat, dan kegiatan lainnya seperti yang ada pada model AIR. Pada saat penelitian nampak bahwa siswa dengan model konvensional kurang aktif dan kurang antusias dalam belajar.

Hasil penelitian ini sejalan hasil penelitian lain. Kemampuan pemecahan masalah siswa melalui model AIR mencapai ketuntasan klasikal (Awaliah,, Soedjoko, \& Isnarto, 2016). Pelaksanaan pembelajaran matematika menggunakan pembelajaran AIR dapat meningkatkan hasil belajar mahasiswa pada materi peluang (Rahayuningsih, 2017). Kemampuan pemecahan masalah matematis peserta didik dipengaruhi oleh penerapan model AIR dengan pendekatan Lesson Study (Agustiana, Putra, \& Farida., 2018). Berdasarkan hasil hasil tersebut, model AIR dapat diterapkan sebagai salah satu cara untuk meningkatkan kemampuan pemahaman dan pemecahaman masalah matematis.

\section{Simpulan}

Model pembelajaran AIR berdampak secara signifikan terhadap kemampuan pemahaman geometri siswa berkemampuan rendah. Oleh karena itu, suatu alternatif untuk menumbuhkan kemampuan pemahaman geometri siswa berkemampuan rendah yaitu melalui penerapan model AIR. 


\section{Ucapan Terima Kasih}

Terima kasih kepada Rektor dan Ketua LPPM Universitas Wiralodra yang telah mendukung penelitian ini. Ucapan terima kasih disampaikan juga kepada Kepala Sekolah SMP Muhammadiyah Segeran dan semua pihak yang telah mengijinkan peneliti melakukan penelitian

\section{Daftar Pustaka}

Agustiana, E., Putra, F. G., \& Farida, F. (2018). Penerapan model pembelajaran Auditory, Intellectually, Repetition (AIR) dengan pendekatan Lesson Study terhadap kemampuan pemecahan masalah matematis peserta didik. Desimal: Jurnal Matematika, 1(1), 1-6. https://doi.org/10.24042/djm.v1i1.1905

Al-Mutawah, A.,M. A., Thomas, R., Eid, A., Mahmoud, E. Y., \& Fateel, M. J. (2019). Conceptual understanding, procedural knowledge and problem-solving skills in mathematics: High school graduates work analysis and standpoints. International Journal of Education and Practice, 7(3), 258-273. https://doi.org/10.18488/journal.61.2019.73.258.273

Amsari, D. (2018). Implikasi teori belajar E. Thorndike (Behavioristik) dalam pembelajaran matematika. Jurnal Basicedu, 2(2), 52-60. https://doi.org/10.31004/basicedu.v2i2.168

Aprianti \& Kesumawati, N. (2019). Pengaruh model Auditory Intellectual Repetition terhadap kemampuan pemecahan masalah ditinjau dari disposisi matematis di SMP. Jurnal Pendidikan Matematika RAFA, 5(1), 10-21. https://doi.org/10.19109/jpmrafa.v5i1.2729

Asfar, A. M. I. T., Asmawaty, A., \& Nursyam, A. (2019). Mathematical concept understanding: the impact of integrated learning model. Al-Jabar: Jurnal Pendidikan Matematika, 10(2), 211-222. https://doi.org/10.24042/ajpm.v10i2.3880

Awaliah, F., Soedjoko, E., \& Isnarto. (2016). Analisis kemampuan pemecahan masalah siswa dalam pembelajaran model Auditory Intellectually Repetition. Unnes Journal of Mathematics Education, 5(3), 243-249. https://doi.org/10.15294/ujme.v5i3.10965

Eriana, Kartono, \& Sugianto. (2018). Understanding ability of mathematical concepts and students' self-reliance towards learning by implementing manipulative props (APM) on Jigsaw technique. Journal of Primary Education, 8(2), 176-183 https://doi.org/10.15294/jpe.v8i2.25984

Fraenkel, J.R., Wallen, N.E, \& Hyun, H. (2012). How to Design and Evaluate Research in Education. Singapore: Mc Graw Hill.

Kemendikbud. (2018). Permendikbud Nomor 35 Tahun 2018 tentang Perubahan atas Peraturan Menteri Pendidikan dan Kebudayaan Nomor 58 Tahun 2014 tentang Kurilkulum Sekolah Menengah Pertama/ Madrasah Tsanawiyah. , Kementerian Pendidikan dan Kebudayaan.

Kemendikbud. (2019). Laporan Hasil Ujian Nasional. Jakarta: Kemendikbud.

Kilpatrick, J., Swafford, J., \& Findel, B. (2001). Adding It UP: Helping Children Learn Mathematics. Washington, DC: National Academy Press.

Lambertus. (2016). Developing skills understanding of mathematical. International Journal of Education and Research, 4(7), 315-326.

Manurung, S. H. (2016). Upaya meningkatkan kreativitas dan hasil belajar matematika siswa dengan menggunakan model AIR (Auditory, Intellectually, Repetition) pada siswa Kelas VIII MTs Negeri Rantauprapat T.P 2014/2015. EduTech: Jurnal Ilmu Pendidikan Dan Ilmu Sosial, 2(1), 97-107. https://doi.org/10.30596/edutech.v2i1.580

Minarni, A., Napitupulu, E. E., \& Husein, R. (2016). Mathematical understanding and representation ability of public junior high school in north Sumatra. Journal on 
Mathematics Education, 7(1), 43-56. https://doi.org/10.22342/jme.7.1.2816.43-56

Mullis, I. V., Martin, M. O., \& Foy, P. (2008). TIMSS 2007. International Mathematics Report. TIMSSEPIRLS International Study Center, Boston College.

Mullis, I. V., Martin, M. O., Foy, P., \& Arora, A. (2012). TIMSS 2011 international results in mathematics TIMSSEPIRLS International Study Center, Boston College.

Mullis, I. V., Martin, M. O., Foy, P., \& Hooper. M. (2016). TIMSS 2015 international results in mathematics. TIMSSEPIRLS International Study Center, Boston College.

Mustamin, S. H. \& Kusumayanti, A. (2019). Kemampuan pemahaman konsep matematika melalui model pembelajaran Auditory Intellectually Repetition (AIR) pada siswa. Alauddin Journal of Mathematics Education, 1(2).90-97.

Nasution, R.A., Rangkuti, A.N., \& Hilda, L. (2019). Upaya guru mengatasi kesulitan siswa belajar matematika pada materi pecahan di kelas VII SMP Negeri 7 Padang Sidimpuan. Logaritma, 7(1), $97-110$.

Novianti, A. (2015). Meningkatkan pemahaman konsep geometri menggunakan benda manipulatif pada siswa kelas V SD Muhammadiyah 4 Batu. INSPIRAMATIKA Jurnal Inovasi Pendidikan dan Pembelajaran Matematika, 1(1), 73-84.

Nur'aini, I. L., Harahap, E., Badruzzaman, F. H., \& Darmawan, D. (2017). Pembelajaran matematika geometri secara realistis dengan GeoGebra. Jurnal Matematika, 16(2). 1-6.

Rahayuningsih, S. (2017). Penerapan model pembelajaran model Auditory Intellectually Repetition (AIR). Erudio: Journal Of Educational Innovation, 3(2), 71-84.

Ramdhan. F, Suwarman, \& Candra, A.U. (2017). Pengaruh model pembelajaran Auditory, Intellectually, Repetition (AIR) terhadap peningkatan pemecahan masalah matematis siswa Prisma, 6 (2), 152-161.

Rohaeti, E., Hendriana, H., \& Sumarmo, U. (2019). Pembelajaran Inovatif Matematika Bernuansa Pendidikan Nilai dan Karakter. Bandung: Refika Aditama.

Runisah, Herman, T., \& Dahlan, J. A. (2017). Using the 5E Learning Cycle with Metacognitive technique to enhance students' mathematical critical thinking skills. International Journal on Emerging Mathematics Education, 1(1), 87-98. http://dx.doi.org/10.12928/ijeme.v1i1.5698

Sarniah, S., Anwar, C., \& Putra, R. W. Y. (2019). Pengaruh model pembelajaran Auditory Intellectually Repetition terhadap kemampuan pemahaman konsep matematis. Journal of Medives: Journal of Mathematics Education IKIP Veteran Semarang, 3(1), 87. https://doi.org/10.31331/medivesveteran.v3i1.709

Shoimin, A. (2014). Model Pembelajaran Inovatif dalam Kurikulum 2013. Yogyakarta: Ar Ruzz media.

Sudirman, S. \& Martadiputra, B. A. P. (2020). Exploratory case study difficulty of junior high school students in resolving problems of the pyramids surface area. Math Didactic: Jurnal Pendidikan Matematika, 6(3), 277-286. https://doi.org/10.33654/math.v6i3.1131

Sudirman, S., Son, A. L., Rosyadi, R., \& Fitriani, R. N. (2020). Uncovering the Students' mathematical concept understanding ability: a based study of both students' cognitive styles dependent and independent field in overcoming the problem of 3D Geometry. Formatif: Jurnal Ilmiah Pendidikan MIPA, 10(1), 1-12. https://doi.org/10.30998/formatif.v10i1.3789

Sumartini, T. S. \& Priatna, N. (2018). Identify student mathematical understanding ability through direct learning model. Journal of Physics: Conference Series, 1132. https://doi.org/10.1088/1742-6596/1132/1/012043

Tularam, G. A. \& Machisella, P. (2018). Traditional vs non-traditional teaching and learning strategies - the case of E-learning! International Journal for Mathematics Teaching and Learning, 19(1), 129-158. 
Runisah, Ismunandar, Sudirman, \& Vianto, Auditory Intellectually Repetition ... 135

Tuna, A. \& Kacar, A. (2013). The effect of 5E learning cycle model in teaching trigonometry on students' academic achievement and the permanence of their knowledge. International Journal on New Trends in Education and Their Implications, 4(1), 73-87. 